\title{
SCAlability of a Graduate AtTributes Assessment AND Continuous Improvement Process
}

\author{
Steven Dew, Robert Driver, Glen Thomas, Mrinal Mandal, and Phillip Choi \\ Faculty of Engineering, University of Alberta \\ steven.dew@ualberta.ca
}

\begin{abstract}
The recent Canadian Engineering Accreditation Board (CEAB) requirements mandating a graduate attributes (GA) assessment and continuous improvement process present a potentially huge burden for assessment, analysis and data management. Designing a robust GA management system and scaling to a large multi-program engineering faculty represents a significant challenge. This paper presents a hierarchical approach developed at the University of Alberta to address these challenges for one of the largest programs in Canada. A set of specific overarching principles has allowed us to significantly reduce the overall task. Key aspects include the exploitation of common indicators and measures where possible. The system currently employs 451 measures and 93,240 individual student assessments vs potentially about 1000 measures and $10^{6}$ student assessments for a similar, but naïve, approach. A multiyear strategy is described to monitor progress and demonstrate a continuous improvement system.
\end{abstract}

Keywords: graduate attributes, accreditation, workload, continuous improvement, scalability, data management

\section{INTRODUCTION}

Ensuring quality of educational programs is of paramount importance in self-regulated professions such as engineering. This function is met in Canada by the Canadian Engineering Accreditation Board (CEAB), which operates from within Engineers Canada [1]. As part of recently adopted new accreditation guidelines [2], $\mathrm{CEAB}$ has stipulated twelve so-called "graduate attributes” (GAs) that engineering programs must demonstrate their students have achieved. Furthermore, engineering schools must demonstrate that they have in place a continuous improvement process to ensure that programs reach progressively higher standards of achievement against those graduate attributes. The GA requirements are fully rolled in as of 2014. The twelve CEAB attributes are as listed in Table 1.
Table 1: CEAB Graduate Attributes [2].

\begin{tabular}{|l|l|}
\hline Knowledge base & Communications skills \\
\hline Problem analysis & Professionalism \\
\hline Investigation & $\begin{array}{l}\text { Impact of engineering on } \\
\text { society and environment }\end{array}$ \\
\hline Design & Ethics and equity \\
\hline Use of engineering tools & $\begin{array}{l}\text { Economics and project } \\
\text { management }\end{array}$ \\
\hline Individual and team work & Life-long learning \\
\hline
\end{tabular}

The challenge of scale becomes apparent from a simple calculation of the requirements for evaluation implied by these CEAB criteria. The University of Alberta (UofA) represents a typical large engineering school with its nine programs [3], each of which is separately accredited. Each of the twelve GAs represents a complex quality that cannot be evaluated with a single metric, so typically 4-6 subattributes (aspects) must be assessed to ensure achievement of that GA. Using fewer than this leaves open the possibility that important components of the attribute are not being assessed. (For example, oral and written communication are two independent aspects of the communication skills graduate attribute and both must be assessed to ensure attainment of that GA.) Simply multiplying 9 programs by 12 attributes and 6 aspects leads to 648 distinct assessments required for demonstrating compliance with the basic CEAB directive. However, given the distinct characteristics of some program options, a desire to establish some entry baselines, and the need for some redundancy in evaluation, the total number of distinct assessments could be much higher. In fact, at the UofA, we average just over 9 distinct assessments per attribute across our nine programs. This suggests the need for almost 1000 different assessments.

If one further presumes that each assessment must be performed for each student (in the spirit of CEAB's historical minimum path approach) the numbers quickly become frightful. The UofA graduates almost 1000 students per year, so this potentially translates into close to one million new data entries each and every year. 
Orchestrating the assessments and collecting, analyzing and managing the data become truly daunting tasks. If the accreditation system in Canada is not to collapse under its own weight, practical strategies are required to mitigate the challenge of the GA criteria. This premise has guided the development of the UofA GA management system.

Fortunately, our cousins in the United States under ABET [4] have been dealing with their own set of GAs for a number of years, and there are lessons there to be learned. One of the key messages of the ABET IDEAL workshops[5] is to manage ambitions when designing a GA system to avoid overloading faculty and staff.

\section{UOFA GRADUATE ATTRIBUTES SYSTEM}

\subsection{Hierarchical Structure}

A common hierarchical structure has been adopted for all programs at the UofA. For each graduate attribute, there are a handful of aspects that articulate the essential components of that GA. These aspects (subattributes) are captured in a short phrase. Table 2 describes the aspects we have identified, some of which vary by program.

Table 2: Aspects identified for each GA. Those in italics are specific to the program (e.g. mechanical engineering)

\begin{tabular}{|c|c|}
\hline GA & Aspects \\
\hline Knowledge base & $\begin{array}{l}\text { mathematics, chemistry, physics, engineering } \\
\text { fundamentals, thermal sciences, solid } \\
\text { mechanics, fluid mechanics, mechanics, } \\
\text { dynamics and control }\end{array}$ \\
\hline \begin{tabular}{|l|} 
Problem \\
analysis
\end{tabular} & $\begin{array}{l}\text { understands the problem, assembles } \\
\text { knowledge, applies models, evaluates result }\end{array}$ \\
\hline Investigation & $\begin{array}{l}\text { recognizes unknowns, measures data, } \\
\text { analyzes data, reaches conclusions }\end{array}$ \\
\hline Design & $\begin{array}{l}\text { requirements, creativity, analysis, iteration, } \\
\text { assessment }\end{array}$ \\
\hline \begin{tabular}{|l} 
Engineering \\
tools
\end{tabular} & $\begin{array}{l}\text { computation, system description, system } \\
\text { modeling, analysis, measurement }\end{array}$ \\
\hline $\begin{array}{l}\text { Individual \& } \\
\text { team work }\end{array}$ & $\begin{array}{l}\text { time management, team work (understands } \\
\text { roles, meets responsibilities, actively } \\
\text { contributes, respects others, leadership) }\end{array}$ \\
\hline Communication & $\begin{array}{l}\text { organized message, writing, reading, } \\
\text { speaking, use of graphics }\end{array}$ \\
\hline Professionalism & $\begin{array}{l}\text { legal responsibilities, licensure requirements, } \\
\text { safety, due diligence }\end{array}$ \\
\hline $\begin{array}{l}\text { Impact on } \\
\text { society }\end{array}$ & $\begin{array}{l}\text { aware of impacts on society, impact } \\
\text { assessment, sustainable design, assessment of } \\
\text { the impacts }\end{array}$ \\
\hline Ethics \& equity & $\begin{array}{l}\text { aware of ethical issues, makes ethical choices, } \\
\text { aware of equity issues, ethics in writing, } \\
\text { appreciation of socio-economic context }\end{array}$ \\
\hline $\begin{array}{l}\text { Economics \& } \\
\text { project mgt. }\end{array}$ & $\begin{array}{l}\text { engineering economics, economic assessment, } \\
\text { project management }\end{array}$ \\
\hline \begin{tabular}{|l|} 
Lifelong \\
learning
\end{tabular} & $\begin{array}{l}\text { curious, able to assess needs, resourceful, } \\
\text { discriminating }\end{array}$ \\
\hline
\end{tabular}

For each aspect, there are one or more indicators, which are structured as tasks that students can carry out to demonstrate that the aspect has been achieved and at which their performance can be assessed objectively. Indicators must be chosen with care and comply with the SMART criteria (specific, measurable, attainable, relevant, timely [6]). For each indicator, there is at least one measure - that is, a context in which the indicator can be assessed effectively. For example, this could be a targeted final exam question within a specified course. We have separated indicators and measures because the same indicator is applied in multiple programs, each of which has a unique context. The intent is that measures will be repeated over time under equivalent conditions, allowing longitudinal tracking of performance. Finally, each measure has a rubric that allows standardized and objective determination of the students' performance levels. We use four levels corresponding to unsatisfactory, developing, satisfactory and excellent.

The result of data collection is a distribution of the population attaining each of the four performance levels. To simplify interpretation at a high program-assessment level, this is reduced to a single value which is the fraction of students who meet at least a satisfactory performance level. This can be compared to a target value to identify GA aspects that need more immediate attention.

For example, consider the Problem Analysis GA for which we have selected the following aspects:

- Understanding the problem (What quantities or criteria are unknown? What are the objectives?)

- Assembling the relevant knowledge (What principles and data are needed?)

- Applying appropriate models (Select and apply the correct equations and methods)

- Evaluating the results (Is the problem solved? Do the values/outcomes obtained make sense?)

Figure 1 provides an example of the resulting indicators, measures and rubrics for the first two of these aspects.

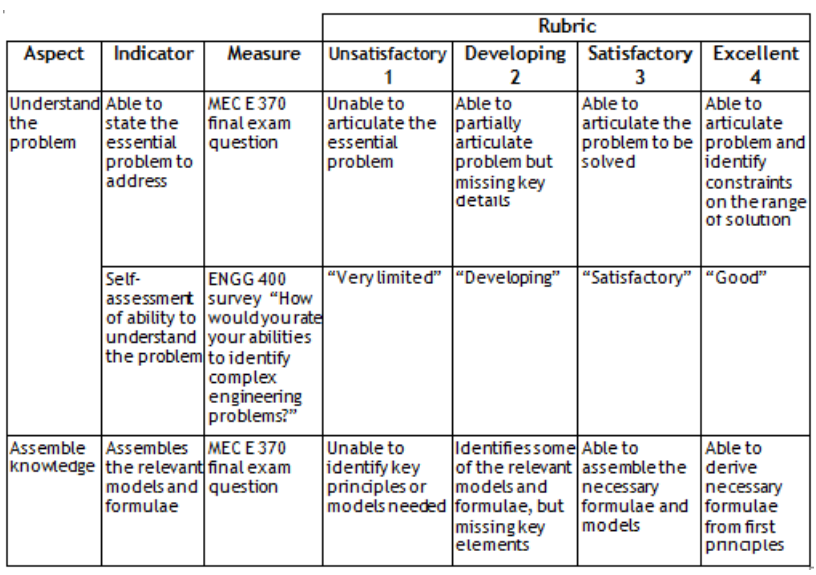

Fig. 1. Portion of the assessment hierarchy for the Problem Analysis GA. 


\subsection{Basic Principles for Indicators}

In developing the necessary indicators, the following principles were adopted:

- As much as possible common indicators and measures should be used across programs. This reduces the number of distinct measures required overall. Some indicators are inherently disciplinespecific, but most are equally applicable to all programs.

- If common measures are not possible, common indicators should still be used when feasible. The same tasks will be performed with the same rubrics, but just in a different context (course). This still allows best practices to be shared and allows better comparisons among programs.

- Where practical, existing activities and data should be used and the data collection process should have little direct impact on the students.

- In general, final student grades are not used as they aggregate multiple GAs and provide little specific information about what might not be working well.

- Where feasible, include both objective (instructor evaluated) and subjective (student evaluated) measures. The former are essential, while the latter are desired as they provide an alternative viewpoint.

- Where multiple measures for an indicator are possible, choose the one latest in the program.

- Measures should be concentrated in a small number of courses if possible. Capstone design courses are particularly relevant. This minimizes instructor training and assessment variability.

- As much as possible, measures are kept within the Faculty of Engineering. Other faculties are less motivated to learn and diligently execute the process.

- Measures need not be made for every student in a program provided that the sample remains large enough to be statistically representative. If there are multiple sections of a course, perhaps only one need be sampled.

- Measures need not be taken every year if historical performance has been acceptable.

- Individuals must be identified in advance to be responsible for collecting each measure.

- A strong baseline of data is needed at the initial implementation stage to facilitate meaningful comparisons in future years. As such, at the UofA three years of collecting data for all indicators in all nine programs was carried out.

\subsection{Curriculum Map}

In order to identify courses and activities that are candidates for GA measures, a curriculum map was developed that plots each course in a program against each of the graduate attributes in terms of where growth towards these attributes is most likely obtained. Figure 2 shows such a map for the Mechanical Engineering program. The values shown in each column correspond to the amount of development of that attribute that occurs within that course on a scale of 0 (none) to 3 (high). For simplicity, zero values are not shown in the figure. In general, measures are taken in the highest level course with a significant level of development (2-3), chosen primarily from program-compulsory or option-compulsory courses.

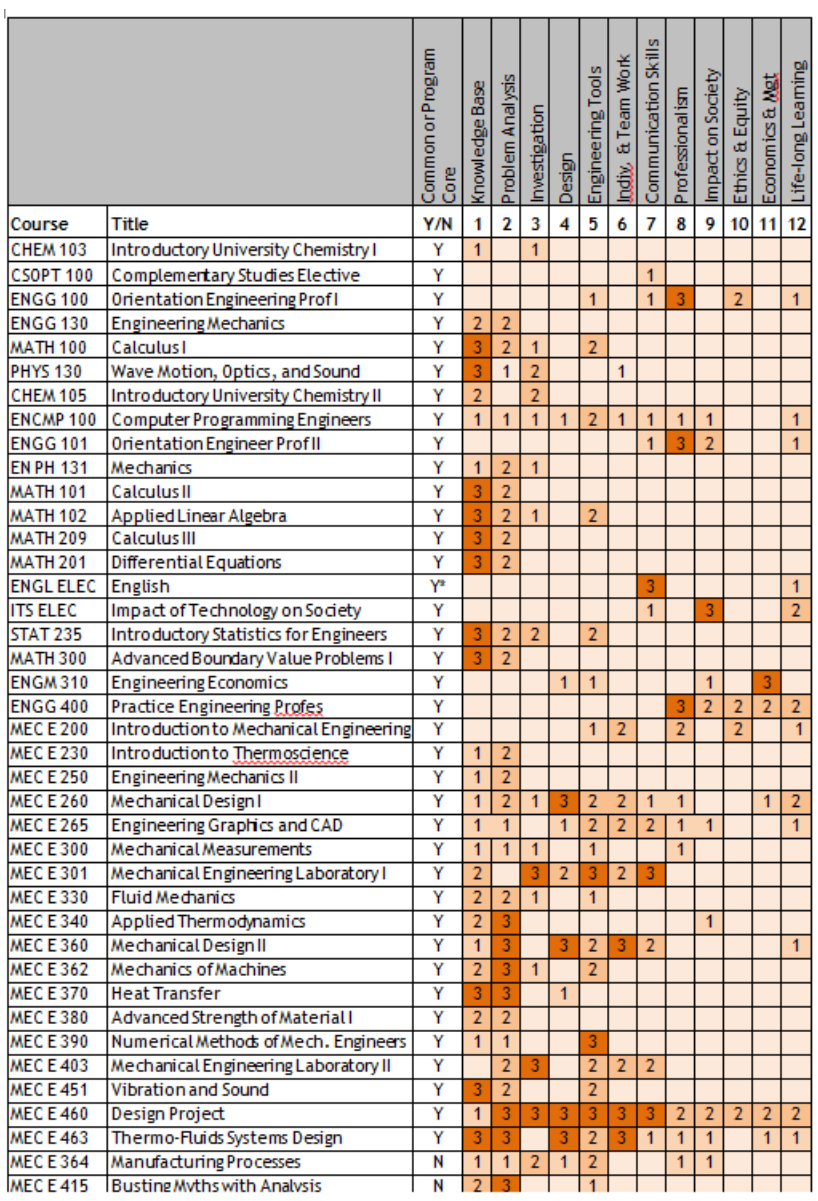

Fig. 2. Excerpt of a curriculum map showing GA development on a scale of 0-3 per course.

An additional value of the curriculum map is that it provides academic planners with a better perspective of the development emphasis for each of the GAs. This may reveal the need for, and subsequently facilitate, reallocation of material and strategy within the curriculum to improve balance and sequencing to, in turn, improve student learning outcomes. 


\subsection{Indicator and Measure Analysis}

Table 3 summarizes the number of measures used across all UofA programs for each of the twelve GAs. Where a measure is used by all programs, it is identified as 'common'. If the same indicator but a different measure is used, it is listed as 'similar'. If two or more programs share a measure by virtue of a common course, it is listed as 'shared'. 'Distinct' measures are specific to a single program.

Also shown in Table 3 is the average number of measures per attribute. This value ranges from just under six (Impact on society and environment) to over nineteen (Knowledge base). This latter result is not surprising given that the GA explicitly refers to "mathematics, natural sciences, engineering fundamentals and specialized engineering knowledge appropriate to the program"[2]. Hence, a large number of measures are needed to cover the wide variety of relevant topics. Knowledge base and Engineering tools also involve the most distinct measures, reflecting the discipline-specific nature of the knowledge and tools employed.

Table 3: Summary of the number of measures for each attribute for all programs.

\begin{tabular}{|l|c|c|c|c|c|c|}
\hline Attribute & Total & Common & Similar & Shared & Distinct & Average \\
\hline Knowledge base & 79 & 12 & 0 & 31 & 36 & 19.4 \\
\hline Problem analysis & 44 & 8 & 36 & 0 & 0 & 12.0 \\
\hline Investigation & 47 & 2 & 45 & 0 & 0 & 7.0 \\
\hline Design & 67 & 2 & 63 & 0 & 2 & 9.2 \\
Engineering tools & 33 & 3 & 0 & 16 & 14 & 6.3 \\
\hline Team work & 69 & 6 & 63 & 0 & 0 & 13.0 \\
Communication & 50 & 2 & 48 & 0 & 0 & 7.3 \\
Professionalism & 7 & 6 & 0 & 0 & 1 & 6.1 \\
Impact on society & 11 & 5 & 0 & 0 & 6 & 5.7 \\
Ethics \& equity & 10 & 8 & 0 & 0 & 2 & 8.2 \\
Economics \& PM & 18 & 5 & 13 & 0 & 0 & 6.4 \\
Lifelong learning & 16 & 8 & 8 & 0 & 0 & 8.9 \\
\hline Total & $\mathbf{4 5 1}$ & $\mathbf{6 7}$ & $\mathbf{2 7 6}$ & $\mathbf{4 7}$ & $\mathbf{6 1}$ & $\mathbf{9 . 1}$ \\
\hline
\end{tabular}

As can be seen from Table 3, there are a total of 451 measures used at the UofA. This is significantly better than the worst case scenario explored above (almost 1000) due to heavy use of common and shared measures. Even when common measures are not possible, the extensive use of similar measures (common indicators) does present some workload advantages.

Table 4: Total measures weighted by number of students

\begin{tabular}{|l|c|c|c|c|}
\hline & \multicolumn{2}{|c|}{ by count } & \multicolumn{2}{c|}{$\begin{array}{c}\text { weighted by } \\
\text { student }\end{array}$} \\
\hline Common & 67 & $14.9 \%$ & 56012 & $60.1 \%$ \\
\hline Similar & 276 & $61.2 \%$ & 25874 & $27.7 \%$ \\
\hline Shared & 47 & $10.4 \%$ & 3638 & $3.9 \%$ \\
\hline Distinct & 61 & $13.5 \%$ & 7716 & $8.3 \%$ \\
\hline Total & 451 & $100 \%$ & 93240 & $100 \%$ \\
\hline
\end{tabular}

Table 4 summarizes these results by measure category, but also factors in the number of students involved. Here is where the advantage of deploying common measures becomes most clear as $60.1 \%$ of the individual evaluations of student performance are able to be shared across all programs. This brings the number of student measures to 93,240 - considerably fewer than the $\sim 1$ million contemplated above under the worst case scenario. Further reductions are possible by sampling only a fraction of the students in these common measures. Since the total population is large, using a subset will still permit an adequate sample size to be maintained. In our case, we have not yet employed reduced-sampling of the common data; instead, we have focused on automation. Most of the common measures data are either entered by students directly into a web-based database as part of their exams or assignments, or it can be extracted from existing university information systems.

\section{ANALYZING DATA}

\subsection{Data Synthesis and Presentation}

Once data from the various measures has been collected, it remains to analyze it. For each program, data is presented by GA. For example, Figure 3 shows the breakdown into the four performance levels of a program's students across each aspect of the Investigation GA. This makes it straightforward to identify the aspects that are well developed and those that may require remedial efforts.

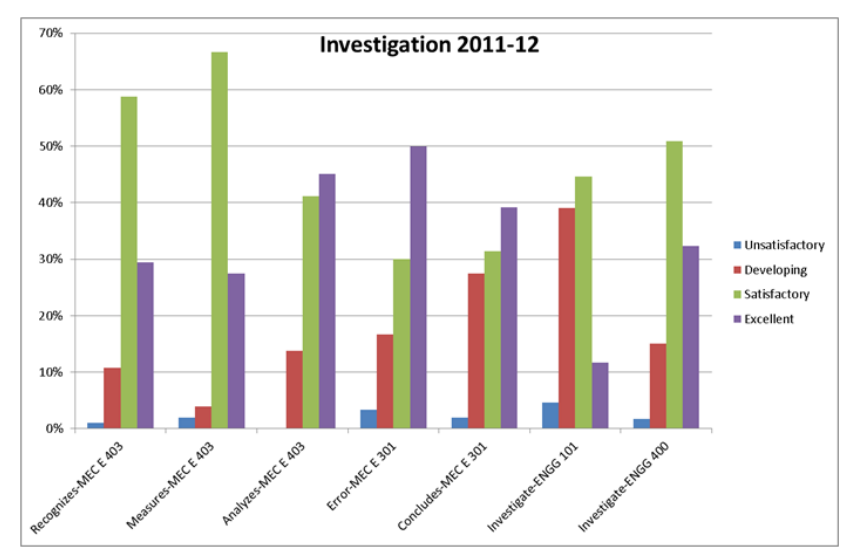

Fig. 3. Distribution of student performance for the set of aspects corresponding to the Investigation GA.

We have developed a formalized process for data analysis. Observations, recommendations and outcomes are recorded on a standardized form that tracks progress through a sequence of individuals and bodies that are responsible for reviewing and approving the GA reports. Typically, that chain involves: 
- Associate Chair or Program Director (Associate Dean for common measures)

- Department Academic Planning Committee

- Faculty Academic Planning Committee

- Executive Coordinating Committee (acting on behalf of the Engineering Faculty Council)

$\mathrm{CEAB}$ requires the demonstration of a quality management system, so this formal process is important to demonstrating that the program quality is not just acceptable, but also under continuous improvement.

It is useful to have a snapshot report of the program's GA health. Figure 4 shows a summary report of performance against target values for each indicator. It must be noted that we have not yet set carefully considered targets and all values are nominally set to $80 \%$ of students achieving at least the satisfactory performance level. Our plan is to analyze and set appropriate targets on a per-measure basis once we have collected three full years of baseline data. Cells in Figure 4 are coloured green if data meets the (nominal) target, red if they do not, or yellow if the data is absent. Indicators without targets are for baseline (first year) measures.

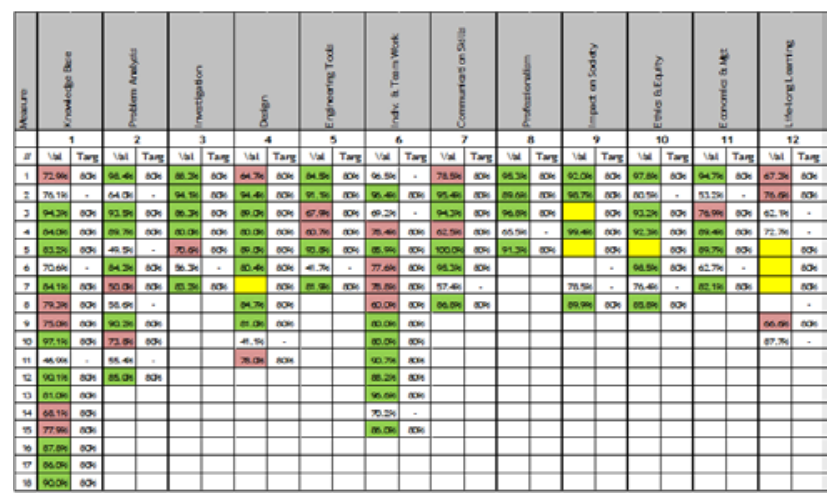

Fig. 4. Summary sheet of performance against (nominal) targets for each measure and all GAs.

An invaluable tool for managing this data has been an Excel spreadsheet that automatically generates the figures, performance metrics and summary sheets from the raw data. The same spreadsheet is also used to record the interpretation and outcomes progress.

\subsection{Year-Over-Year Measurement and Analysis}

CEAB expects a continuous improvement process that clearly requires data collection and analysis on a regular and ongoing basis. Given academic cycles, an annual frequency makes the most sense for this process. However, in steady state, we do not expect that every measure need be assessed every year. For aspects which appear to be comfortably meeting targets, we are planning on a three year cycle so that two complete iterations of the
GA collection cycle are completed for each six year $\mathrm{CEAB}$ visit. In the first year of the cycle, data for one third of the GAs are collected. In the second year, that data is evaluated and an action plan is developed, while the next third of the data is collected. In the third year, changes are implemented as per the action plan for the first third, while the remaining fractions proceed through the same steps but offset in one year intervals. This plan is laid out in Table 5.

Table 5: GA roll-in and three year management cycle.

\begin{tabular}{|l|l|l|l|}
\hline Year & $\begin{array}{c}\text { Measure } \\
\text { and assess }\end{array}$ & $\begin{array}{c}\text { Evaluate and } \\
\text { plan }\end{array}$ & $\begin{array}{c}\text { Implement } \\
\text { changes }\end{array}$ \\
\hline $2011-12$ & All GAs & & \\
\hline $2012-13$ & All GAs & All GAs & \\
\hline $2013-14$ & All GAs & All GAs & All GAs \\
\hline $2014-15$ & $1,4,7,10$ & $3,6,9,12$ & $2,5,8,11$ \\
\hline $2015-16$ & $2,5,8,11$ & $1,4,7,10$ & $3,6,9,12$ \\
\hline $2016-17$ & $3,6,9,12$ & $2,5,8,11$ & $1,4,7,10$ \\
\hline $2017-18$ & $1,4,7,10$ & $3,6,9,12$ & $2,5,8,11$ \\
\hline
\end{tabular}

So far, we only have two complete years of data. Figure 5 presents the performance for one of our programs in the Investigation GA in Year 1 (red) and Year 2 (blue) compared with the nominal target (green). Some degree of variability can be seen in the year-over-year behaviour, but further data will be required before conclusions about trends can be made.

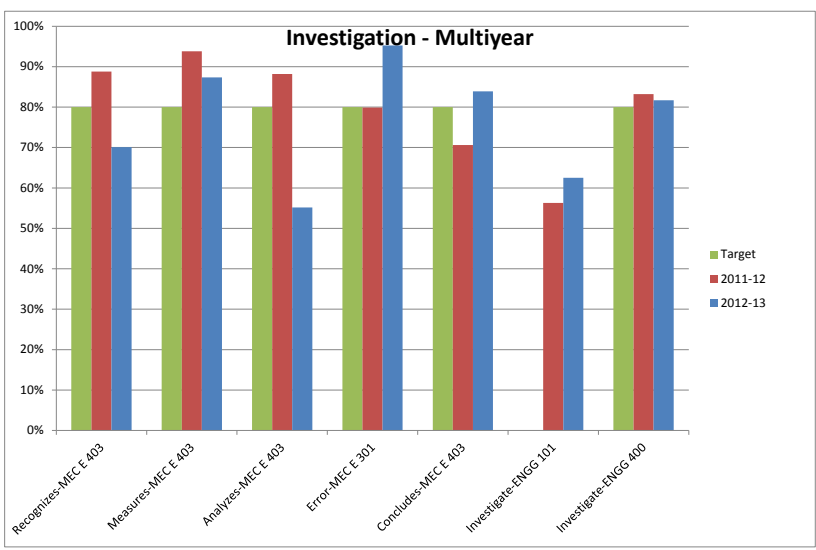

Fig. 5. Multiyear trend in performance for the Investigation GA.

We expect development of the GA management system to be an iterative process, and a comprehensive review is planned after the completion of Year 3. Some measures have proven to be impractical and will have to be adjusted. However, a high degree of consistency and discipline is required to make valid year-over-year comparisons, so continual adjustments to the process should be avoided. 


\section{CONCLUSIONS}

Implementation of a CEAB-compliant graduate attributes measurement and continuous improvement system involves a huge undertaking in the collection, analysis, and management of data. A set of principles have been established that have allowed the University of Alberta to significantly reduce that undertaking. Our approach involves a hierarchical structure of graduate attributes, aspects, indicators, measures and rubrics. By using common and shared measures whenever possible, total assessment load is reduced. Sharing indicators, when sharing measures is not feasible, still allows benefits.

A multiyear strategy is required to further reduce the assessment burden and to provide a mechanism to track and document a continuous improvement process.

\section{Acknowledgements}

The authors represent the team responsible for developing the GA management system at the UofA. Additional individuals who made important contributions include Profs. Larry Kostiuk and Robert Koch. Their efforts are gratefully acknowledged here.

\section{References}

[1] Engineers Canada is the national organization representing the provincial and territorial associations that regulate the profession of engineering in Canada. See http://www.engineerscanada.ca

[2] 2013 Canadian Engineering Accreditation Board Accreditation Criteria and Procedures, pp. 13-14. See http://www.engineerscanada.ca/sites/default/files/sites/defau lt/files/accreditation_criteria_procedures_2013.pdf

[3] The University of Alberta offers 9 undergraduate programs in engineering. Programs are described in section 80 of the university Calendar. See http://www.registrar.ualberta.ca/calendar/Undergrad/Engine ering/index.html

[4] ABET is a national US organization that accredits applied science, computing, engineering and engineering technology programs. See http://www.abet.org

[5] ABET Institute for the Development of Excellence in Assessment Leadership (IDEAL) program. See http://www.abet.org/ideal/

[6] Doran, G. T. “There's a S.M.A.R.T. way to write management's goals and objectives”. Management Review, vol.70, no. 11, pp. 35-36, 1981. 